\title{
An apoplastic fluid extraction method for the characterization of grapevine leaves proteome and metabolome from a single sample
}

\author{
Joana Figueiredo ${ }^{a, b, c}$, Ana Rita Cavaco ${ }^{a}$, Leonor Guerra-Guimarães ${ }^{d, e, *}$, Céline Leclercq ${ }^{f}$, Jenny Renaut ${ }^{f}$, \\ Jorge Cunha ${ }^{g}$, José Eiras-Dias ${ }^{9}$, Carlos Cordeiro ${ }^{b, c}$, Ana Rita Matos ${ }^{a}$, Marta Sousa Silva ${ }^{b, c}$ and \\ Andreia Figueiredo ${ }^{\mathrm{a}, *}$ (1) \\ aUniversity of Lisboa, Faculty of Sciences, BioISI - Biosystems \& Integrative Sciences Institute, Lisbon, Portugal \\ bLaboratório de FTICR e Espectrometria de Massa Estrutural, Faculdade de Ciências da Universidade de Lisboa, Lisbon, Portugal \\ 'Departamento de Química e Bioquímica, Faculdade de Ciências da Universidade de Lisboa, Lisbon, Portugal \\ ${ }^{d}$ Centro de Investigação das Ferrugens do Cafeeiro, Instituto Superior de Agronomia, Universidade de Lisboa, Oeiras, Portugal \\ eLinking Landscape, Environment, Agriculture and Food, Instituto Superior de Agronomia, Universidade de Lisboa, Lisbon, Portugal \\ fLuxembourg Institute of Science and Technology, Belvaux, Luxembourg \\ IInstituto Nacional de Investigação Agrária e Veterinária - Estação Vitivinícola Nacional, Dois Portos, Portugal
}

\section{Correspondence \\ *Corresponding authors, \\ e-mails: leonorguimaraes@isa.ulisboa.pt; \\ aafigueiredo@fc.ul.pt}

Received 29 May 2020;

revised 19 August 2020

doi:10.1111/ppl.13198
The analysis of complex biological systems keeps challenging researchers. The main goal of systems biology is to decipher interactions within cells, by integrating datasets from large scale analytical approaches including transcriptomics, proteomics and metabolomics and more specialized 'OMICS' such as epigenomics and lipidomics. Studying different cellular compartments allows a broader understanding of cell dynamics. Plant apoplast, the cellular compartment external to the plasma membrane including the cell wall, is particularly demanding to analyze. Despite our knowledge on apoplast involvement on several processes from cell growth to stress responses, its dynamics is still poorly known due to the lack of efficient extraction processes adequate to each plant system. Analyzing woody plants such as grapevine raises even more challenges. Grapevine is among the most important fruit crops worldwide and a wider characterization of its apoplast is essential for a deeper understanding of its physiology and cellular mechanisms. Here, we describe, for the first time, a vacuum-infiltrationcentrifugation method that allows a simultaneous extraction of grapevine apoplastic proteins and metabolites from leaves on a single sample, compatible with high-throughput mass spectrometry analyses. The extracted apoplast from two grapevine cultivars, Vitis vinifera cv 'Trincadeira' and 'Regent', was directly used for proteomics and metabolomics analysis. The proteome was analyzed by nanoLC-MS/MS and more than 700 common proteins were identified, with highly diverse biological functions. The metabolome profile through FT-ICR-MS allowed the identification of 514 unique putative compounds revealing a broad spectrum of molecular classes.

Abbreviations - APF, apoplastic fluid; C16:0, palmitic acid; C16:1 $t$, trans-3-hexadecanoic acid; C17:0, margaric acid; C18:0, stearic acid; C18:1, oleic acid; C18:2, linoleic acid; C18:3, $\alpha$-linolenic acid; ECS, extracellular space; ESI, electrospray ionization; FA, fatty acid; $M D H$, malate dehydrogenase; $M S$, mass spectrometry; NAD, nicotinamide adenine dinucleotide; PG, phosphatidylglycerol; PMS, phenazine methosulphate; SP, signal peptide; VIC, vacuum-infiltration-centrifugation. 


\section{Introduction}

The apoplast, referred to as a synonym of extracellular space (ECS), is formed by the whole compartment external to the plant plasma membrane that includes the cell wall, the free space between cells (or intercellular space) and the apoplastic fluid (APF) (Guerra-Guimarães et al. 2016). In the beginning of the past century, due to the lack of methods and experimental approaches for the correct study of this compartment in vivo (Chikov et al. 2019), there was a firm belief that the extracellular space contained mainly water, minerals and lowmolecular weight compounds involved in metabolism (Dixon 1915). The difficulty in obtaining sufficient apoplastic material without damaging the plant cell and, thus, avoiding potential contamination with cytoplasmic contents also contributed to the delay in APF characterization. Over the last decade, technological advances (e.g. mass spectrometry analysis and database information availability) allowed a thorough characterization of this highly dynamic compartment highlighting its role in cellular metabolism (Lohaus et al. 2001, Delaunois et al. 2014). The ECS participates in plant signaling, growth, physiology, cell wall maintenance and reproduction and is affected by environmental conditions (Ellis et al. 2007, Tseng et al. 2009). In the case of roots, microorganisms that colonize this compartment contribute to the nutrition of higher plants through its ability to fix di-nitrogen (reviewed in Sattelmacher 2001). Apoplast is also responsible for water vapor and gas exchange involved in transpiration and photosynthesis, and for amino acid trafficking to the phloem (Gentzel et al. 2019).

APF studies have also uncovered plant's secretome that comprises the set of all proteins and small molecules that are exported out of the symplast. Several roles were assigned to secreted proteins through APF proteomics approaches (reviewed in Agrawal et al. 2010, Alexandersson et al. 2013, Krause et al. 2013, Delaunois et al. 2014, Guerra-Guimarães et al. 2016). In contrast, transcriptomic (Blomster et al. 2011) and metabolomic (Floerl et al. 2012, O'Leary et al. 2016, Green et al. 2020) studies of plant apoplast are rare and in what concerns lipidomics it remains a black box (Misra 2016).

The most commonly used technique for plant APF extraction is the vacuum infiltration-centrifugation (VIC), described by Klement and co-workers in 1965 (Klement 1965), consisting on vacuum-infiltration with appropriate extraction buffer and centrifugation (Lohaus et al. 2001). The composition of the extraction buffer and both infiltration and centrifugation procedures may vary significantly depending on the plant species and the downstream goal of the APF extraction. Several detailed centrifugation-based methods for extracting APF from plant leaves were described for herbaceous plants as Arabidopsis (Floerl et al. 2012, Villiers and Kwak 2013), common bean (Lohaus et al. 2001, O'Leary et al. 2016), maize (Lohaus et al. 2001, Gentzel et al. 2019); faba bean, peas, spinach (Lohaus et al. 2001), among others. For woody plants, leaf infiltration raises more challenges because of the morphology of the leaves that impairs the infiltration buffer accessibility, but several VIC-based studies were also described for poplar, eucalyptus, prunus, bitter orange tree, apricot, peach, grapevine, coffee and Arabidopsis (Boudart et al. 2005, Diaz-Vivancos et al. 2006, Ros-Barceló et al. 2006, Pechanova et al. 2010, Delaunois et al. 2013, GuerraGuimarães et al. 2015).

Grapevine (Vitis vinifera L.) is one of the most valuable fruit crops worldwide, representing $7.4 \mathrm{kHa}$ of the cultivated area in 2018 (data from the 2019 Statistical Report on World Vitiviniculture, International Organization of Vine and Wine). In the last year, 292 million hectolitres $(\mathrm{mhL})$ of wine were produced all over the world, making the wine industry one of the most important economic sectors in several countries. In this study, two $V$. vinifera cultivars 'Trincadeira' and 'Regent' were used as plant models. 'Trincadeira' is one of the most widely planted red grape cultivars in Portugal and 'Regent' is a darkskinned crossing line grape cultivar created in Germany. In Portugal, 'Regent' is not authorized for wine production (MAMAOT 2012) and its plantation is restricted to the germplasm bank. It presents resistance loci to Plasmopara viticola (loci RPV3.1) and to Erysiphe necator (loci RUN3 and RUN9), the downy and powdery mildews causing agents, respectively, and thus it is useful as donor of tolerance genes to cryptogamic disease whenever included in breeding programs of Portuguese autochthonous cultivars.

In the last decade, almost 10000 studies were conducted on grapevine (NCBI, https://www.ncbi.nlm.nih. gov/, accessed in May, 2020), encompassing studies in all its tissues, at constitutive level as well as under environmental and human-induced stimuli, using different technologies and analyzing diverse OMICs. Genomics, transcriptomics, proteomics and metabolomics have been the most explored to unravel the different physiological processes and response mechanisms that are activated and repressed under several conditions. However, only two papers focusing on grapevine leaf APF proteomics were published so far (Delaunois et al. 2013, Guillier et al. 2015) and none on APF metabolomics. A more comprehensive analysis of this compartment in grapevine leaf may uncover molecules that participate in intercellular communication, transport and plantenvironment interaction. Here, we developed an APF 
extraction method to obtain a simultaneous extraction of proteins and metabolites from the same sample, compatible with direct analysis of the proteome and metabolome by mass spectrometry (MS). This study will open new possibilities for a more comprehensive study of grapevine leaf APF.

\section{Materials and methods}

\section{Plant material}

Two grapevine cultivars $V$. vinifera 'Trincadeira' and 'Regent' with different phenological characteristics were used. Young fully expanded leaves, from both cultivars, grown in greenhouse at the Portuguese Grapevine Germplasm Bank (PRT051) at INIAV - Estação Vitivinícola Nacional (Dois Portos, Portugal), were harvested. Leaves from the third to fifth position from the shoot apex were collected from 15 to 20 plants. Plant growth conditions were standardized for both cultivars, growing under a light cycle of 14-10 h (light/dark) with temperature and relative humidity ranging between $25-18^{\circ} \mathrm{C}$ and 40-60\%, respectively. Leaves' harvest occurred 2-3 h into the light period and plants were watered in the previous day. Hydration conditions were the same for both 'Regent' and 'Trincadeira'. Leaves were washed in distilled water, disinfected in a bleach solution $(5.5 \%$ sodium hypochlorite) for $1 \mathrm{~min}$ and $30 \mathrm{~s}$ and then rinsed three times in distilled water. Leaves were dried with sterile filter paper and immediately used for apoplast extraction. Leaf material was also collected and immediately frozen in liquid nitrogen and kept at $-80^{\circ} \mathrm{C}$ for extraction of total soluble proteins and fatty acids.

\section{Apoplastic fluid extraction}

Apoplastic fluid was extracted according to GuerraGuimarães et al. (2015) with minor modifications. Twenty-five grams of fresh material (corresponding to approximately 30 young fully expanded leaves) from both grapevine cultivars were used. Leaves were cut in small fragments (approximately $2 \mathrm{~cm}^{2}$ ) and vacuum infiltrated ( $25 \mathrm{kPa}$ ) with $0.1 \mathrm{M}$ Tris- $\mathrm{HCl}$ buffer $(\mathrm{pH} 8.0)$ solution containing $0.5 \mathrm{M} \mathrm{KCl}, 0.006 \mathrm{M} \mathrm{CHAPS}$ and $2 \%(\mathrm{w} / \mathrm{v})$ $\mathrm{Na}_{2} \mathrm{SO}_{3}$ (at $4{ }^{\circ} \mathrm{C}$ ), for six cycles of $30 \mathrm{~s}$. After infiltration, fragments were washed in cold distilled water and centrifuged at $5000 \mathrm{~g}$, during $15 \mathrm{~min}$ at $4^{\circ} \mathrm{C}$, the APF was collected and stored at $-20^{\circ} \mathrm{C}$ (Fig. 1A). All steps of the protocol were performed at $4^{\circ} \mathrm{C}$, including leaf cutting, lab material and buffers to minimize the impact of the technical procedure and preserve the biological samples.

\section{Extraction of total soluble proteins}

Leaves from both grapevine cultivars were grinded with liquid nitrogen. A volume of $1.2 \mathrm{ml}$ of $0.2 \mathrm{M} \mathrm{Tris- \textrm {HCl }}$ buffer $(\mathrm{pH}$ 8.2) solution containing, $0.14 \mathrm{M} \mathrm{NaCl}$, $0.05 \%(\mathrm{v} / \mathrm{v})$ Tween $20,0.2 \%(\mathrm{w} / \mathrm{v})$ bovine serum albumin (BSA), $2 \%(\mathrm{w} / \mathrm{v}) \mathrm{Na}_{2} \mathrm{SO}_{3}, 2 \%(\mathrm{w} / \mathrm{v})$ polyvinylpyrrolidone (PVP) K25, insoluble PVP $(1: 1, w / w)$ was added to $150 \mathrm{mg}$ of leaves. Samples were vortexed and incubated on ice during $30 \mathrm{~min}$ with agitation. The homogenate was centrifuged at $14000 \mathrm{~g}$, during $15 \mathrm{~min}$ at $4^{\circ} \mathrm{C}$

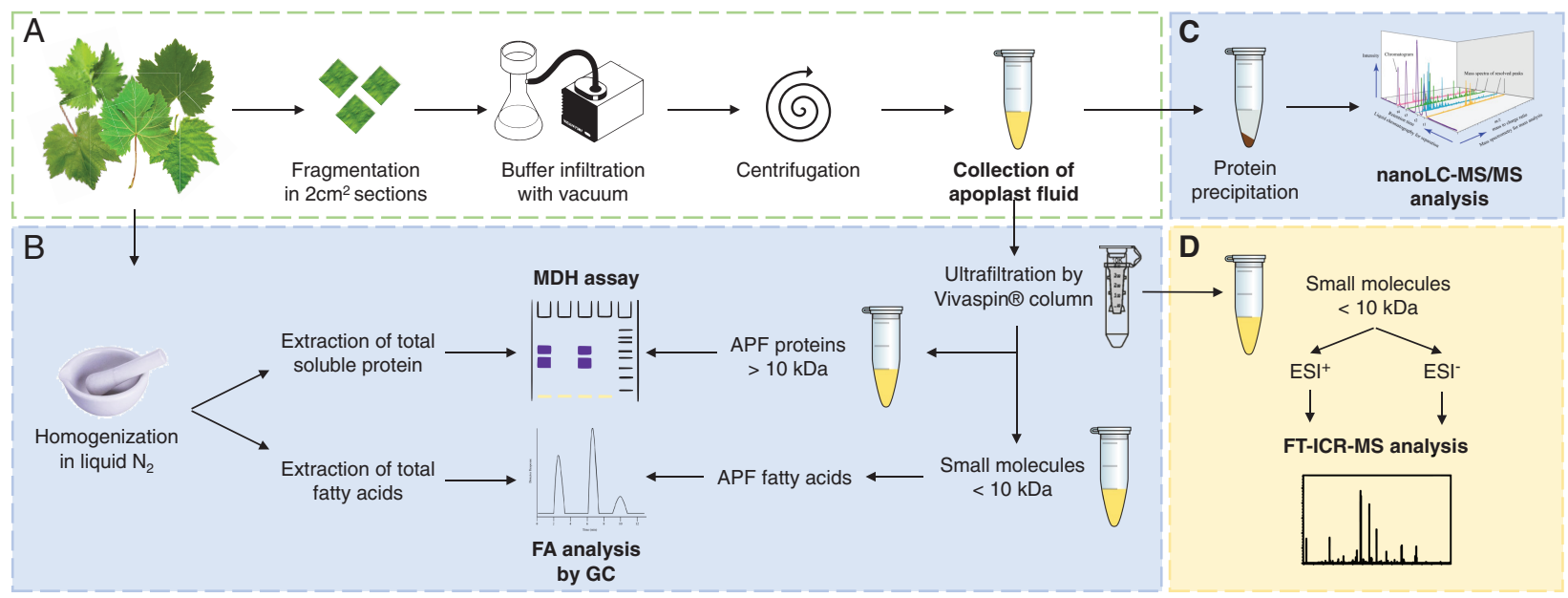

Fig 1. Experimental workflow. (A) Grapevine leaves apoplast fluid extraction. (B) Purity assessment of apoplastic fluid based on malate dehydrogenase $(\mathrm{MDH})$ assay and fatty acids (FA) identification by gas chromatography (GC). (C) Proteomic analysis by nanoscale liquid chromatography coupled to tandem mass spectrometry (nanoLC-MS/MS). (D) Metabolomic analysis by Fourier transform-ion cyclotron resonance-mass spectrometry (FT-ICR-MS), in positive $\left(\mathrm{ESI}^{+}\right)$and negative $\left(\mathrm{ESI}^{-}\right)$ionization modes. 
(Diniz et al. 2019), and the supernatant was collected and store at $-20^{\circ} \mathrm{C}$.

The protein content of the extracts was quantified based on the Bradford method using the Bio-Rad protein assay protocol for microtiter plates (according to manufacturer's instructions). A bovine serum albumin (BSA) was used as standard and absorbance was measured at $595 \mathrm{~nm}$.

\section{Malate dehydrogenase assay}

The APF extracts were desalted and concentrated on Vivaspin $\AA$ columns with a membrane ultrafiltration of $10 \mathrm{kDa}$ (Sartorius), according to manufacturer's instructions. Malate dehydrogenase (MDH) identification, used as a cytosolic biomarker, was performed in both APF (protein present in the upper fraction $>10 \mathrm{kDa}$ ) and total soluble protein extracts. Proteins were analyzed by isoelectric focusing electrophoresis (IEF) on $5 \%$ polyacrylamide gel with $2 \%$ ampholyte $\mathrm{pH} 3-10$ (Servalyt of SERVA), performed according to Loureiro et al. (2011) and Robertson et al. (1987). After protein migration, the gel was incubated in $0.1 \mathrm{M}$ Tris- $\mathrm{HCl}$ buffer $\mathrm{pH} 8.5$ containing $0.025 \%(\mathrm{w} / \mathrm{v})$ nicotinamide adenine dinucleotide (NAD), $10 \%(\mathrm{v} / \mathrm{v}) 1 \mathrm{M}$ sodium hydrogen malate, $0.02 \%$ $(\mathrm{w} / \mathrm{v})$ nitroblue tetrazolium (NBT), $0.001 \%(\mathrm{w} / \mathrm{v})$ phenazine methosulfate (PMS), in the dark at $40^{\circ} \mathrm{C}$. The appearance of purple-blue bands indicates the presence of MDH (Shaw and Prasad 1970; Fig. 1B).

\section{Fatty acid analysis}

The detection of the trans-3-hexadecenoic acid (C16:1 t), a plastidial fatty acid (FA), was performed in both APF and total grapevine leaf extracts to assess apoplastic fluid quality. For FA analysis, $150 \mu \mathrm{l}$ of the APF fraction below $<10 \mathrm{kDa}$, obtained after ultrafiltration, were used. For total extracts, $50 \mathrm{mg}$ of grinded leaves were used per cultivar. Twenty micrograms of margaric acid (C17:0), used as internal standard, were added to each sample (APF and total extracts), followed by the addition of $3 \mathrm{ml}$ of methanol-sulfuric acid solution (39:1 v/v). The methylation reaction occurred for $1 \mathrm{~h}$ at $70^{\circ} \mathrm{C}$ and was stopped by cooling. The methyl esters were recovered by adding petroleum ether and ultrapure water $(3: 2, \mathrm{v} / \mathrm{v})$ and the organic phase was collected. The organic phase was dried at $37^{\circ} \mathrm{C}$ under nitrogen atmosphere and resuspended in $20 \mu \mathrm{l}$ hexane with $1 \mu \mathrm{l}$ of sample injected for each analysis. FAs quantitative analysis was performed using gas chromatography (430GC Gas Chromatograph, Varian) as described before (Esquível et al. 2017; Fig. 1B). Five technical replicates were done.

\section{Proteomic analysis by nanoLC-MS/MS}

\section{APF protein precipitation}

The proteins were precipitated using 5 volumes of $0.1 \mathrm{M}$ ammonium acetate in methanol and kept overnight at $-20^{\circ} \mathrm{C}$. The samples were centrifuged at $4000 \mathrm{~g}$, during $30 \mathrm{~min}$ at $-10^{\circ} \mathrm{C}$ and the pellets were recovered. The pellets were washed once with $0.1 \mathrm{M}$ ammonium acetate in $100 \%$ methanol, twice with $80 \%(\mathrm{v} / \mathrm{v})$ acetone and twice with $70 \%(\mathrm{v} / \mathrm{v})$ ethanol (Sebastiana et al. 2013). The pellets were dried and resuspended in $0.03 \mathrm{M}$ Tris- $\mathrm{HCl}$ buffer $(\mathrm{pH}$ 8.8) solution containing, $7 \mathrm{M}$ urea, $2 \mathrm{M}$ thiourea, 4\% (w/v) CHAPS (Guerra-Guimarães et al. 2015) (Fig. 1C). Protein quantification was performed with RC DCTM protein assay kit (Bio-Rad) according to the manufacturer's procedure (Ramagli 1999).

\section{MS-based protein identification}

Twenty micrograms of protein were separated on a precast gel (Criterion ${ }^{\mathrm{TM}}$ XT precast 1D gel $4-12 \%$ Bis-Tris, Bio-Rad) and then stained with Instant Blue (Gentaur BVBA). Proteins were reduced, alkylated then digested by trypsin enzyme (sequencing mass grade, Promega; Granvogl et al. 2007). Protein identification was achieved by nanoLC-MS/MS using a nanoLC-425 Eksigent system coupled to high-resolution MS TripleTOF ${ }^{\circledR}$ 6600 (SCIEX). Extracted peptides were solubilized and loaded on a C18 pre-column (C18 PepMap ${ }^{\mathrm{TM}}, 5 \mu \mathrm{m}$, $5 \mathrm{~mm} \times 300 \mu \mathrm{m}$, Thermo scientific) for $10 \mathrm{~min}$ at a flow rate of $2 \mu \mathrm{l} / \mathrm{min}$ using loading buffer $(2 \%(\mathrm{v} / \mathrm{v})$ acetonitrile, $0.05 \%(\mathrm{v} / \mathrm{v})$ trifluoroacetic acid). Then, peptides were separated with a C18 reverse-phase column (C18 PepMap ${ }^{\mathrm{TM}} 100,3 \mu \mathrm{m}, 100 \AA, 75 \mu \mathrm{m} \times 15 \mathrm{~cm}$, Thermo scientific) using a linear binary gradient (solvent $A$ : $0.1 \%(\mathrm{v} / \mathrm{v})$ formic acid; solvent B: $0.1 \%(\mathrm{v} / \mathrm{v})$ formic acid in acetonitrile) at a flow rate of $300 \mathrm{nl} / \mathrm{min}$. Peptides were eluted from 3 to $30 \%$ solvent $B$ over $60 \mathrm{~min}$, increased to $40 \% \mathrm{~B}$ during $10 \mathrm{~min}$ then to $80 \%$ B until $5 \mathrm{~min}$. The column was regenerated by washing for $7 \mathrm{~min}$ at $80 \% \mathrm{~B}$ and re-equilibrated for $18 \mathrm{~min}$ at $3 \% \mathrm{~B}$.

The data were acquired in positive nano-electrospray (nano-ESI ${ }^{+}$) mode set to obtain a high resolution TOFMS scans over a mass range 300-1250 m/z. The 30 most intense precursors were selected for fragmentation in high sensitivity mode (MS/MS scans range 100$1500 \mathrm{~m} / \mathrm{z}$ ) using the automatically adjusted system of rolling collision energy voltage. The ion accumulation time was set to $250 \mathrm{~ms}$ (MS) and to $50 \mathrm{~ms}$ (MS/MS). The MS data were imported into Progenesis QI for Proteomics software (v.4.1, Nonlinear Dynamics, Waters). The protein and peptide identification searching NCBlprot Vitis vinifera database released on 20th of February 2019 (208 304 sequences) via Mascot Daemon (v.2.6.0. 
Matrix Science) were imported to Progenesis QIP and matched to peptide spectra. The Mascot research parameters were: a peptide tolerance of $20 \mathrm{ppm}$, a fragment mass tolerance of $0.3 \mathrm{Da}$, carbamidomethylation of cysteine as fixed modification and oxidation of methionine, $\mathrm{N}$-terminal protein acetylation and tryptophan to kynurenine as variable modifications. Only the proteins identified with a significance MASCOT-calculated threshold $P$-value $<0.05$, at least two significant peptides per proteins and one unique peptide per proteins were accepted.

The mass spectrometry proteomics data have been deposited to the ProteomeXchange Consortium (Deutsch et al. 2017) via the PRIDE (Vizcaíno et al. 2016) partner repository with the dataset identifier PXD015558 and 10.6019/PXD015558.

\section{Further proteomic data processing}

The identified proteins were classified based on Enzyme Commission number using Blast2GO software (version 5.2.5, https://www.blast2go.com/, Conesa et al. 2005). The functional annotation of the identified proteins was performed based on MapMan 'Bincode' ontology (http://mapman.gabipd.org/web/guest/mapman) using Mercator Automated Sequence Annotation Pipeline (http://mapman.gabipd.org/web/guest/app/mercator, Lohse et al. 2014) and Gene Ontology annotation using Blast2GO software. The subcellular localization prediction of the proteins was performed using SignalP 5.0, TargetP 1.1 and SecretomeP 2.0 servers (http://www.cbs.dtu.dk/services/, Bendtsen et al. 2004, Emanuelsson et al. 2007, Almagro Armenteros et al. 2019), ApoplastP (http://apoplastp.csiro. $\mathrm{au} / \_$Sperschneider et al. 2018), BUSCA (http://busca. biocomp.unibo.it/, Savojardo et al. 2018), LocTree3 (https:// rostlab.org/services/loctree3/, Goldberg et al. 2014), Mercator (https://www.plabipd.de/portal/mercator-sequenceannotation, Lohse et al. 2014) and Blast2GO. The default parameters were used for all the programs.

\section{Metabolomic analysis by FT-ICR-MS}

The APF extracts were filtered through the Vivaspin ${ }^{\circledR}$ columns and the fraction below $<10 \mathrm{kDa}$ was analyzed by direct injection in a Fourier Transform-lon Cyclotron Resonance (FT-ICR) mass spectrometer, operating in positive $\left(\mathrm{ESI}^{+}\right)$and negative $\left(\mathrm{ESI}^{-}\right)$ionization modes (Fig. 1D). The samples were diluted 1000-fold in methanol before injection (Maia et al. 2016). Formic acid (final concentration $0.1 \%(\mathrm{v} / \mathrm{v})$, Sigma Aldrich, MS grade) was added for samples analyzed in positive ion mode. Leucineenkephalin (YGGFL, Sigma Aldrich) was added to all samples at a concentration of $0.5 \mu \mathrm{g} \mathrm{ml}^{-1}$ and used as a standard for control and quality assessment of analytical precision $\left([\mathrm{M}+\mathrm{H}]^{+}=556.276575 \mathrm{Da}\right.$ or $[\mathrm{M}-$
$\mathrm{H}]^{-}=554.260925 \mathrm{Da}$ ) and for internal online calibration during sample acquisition. Samples were analyzed by direct infusion on the 7-Tesla SolariX XR FT-ICR-MS equipped with ParaCell (Bruker Daltonics). Mass spectra were recorded in a mass range $100-1000 \mathrm{~m} / \mathrm{z}$ and 200 scans were accumulated. Five technical replicates were analyzed for each grapevine cultivar.

Data Analysis 4.1 software package (Bruker Daltonics) was used to analyze the spectra and generate the peak list further exported as ASCII files with a signal-to-noise ratio of 4 . The mass list for each sample was submitted to MassTRIX 3 server (http://masstrix.org, accessed in March 2019, Suhre and Schmitt-Kopplin 2008). The parameters considered were the following: scan mode was either positive or negative; the adducts $\mathrm{M}+\mathrm{H}^{+}, \mathrm{M}+\mathrm{K}^{+}$and $\mathrm{M}$ $+\mathrm{Na}^{+}$were chosen for positive scan mode; the adducts $\mathrm{M}-\mathrm{H}^{+}$and $\mathrm{M}+\mathrm{Cl}^{-}$were selected for negative scan mode; $1 \mathrm{ppm}$ was the maximum $\mathrm{m} / \mathrm{z}$ deviation considered; Vitis vinifera was selected as the organism; the search was performed in the databases KEGG (Kyoto Encyclopedia of Genes and Genomes)/HMDB (Human Metabolome Database)/LipidMaps without isotopes. Masses that existed in at least three of the five replicates were considered.

For each ionization mode, the obtained mass lists of 'Trincadeira' and 'Regent' were merged and the common compounds were analyzed. Compound classification was performed as previously described (Nascimento et al. 2019). Briefly, for each putatively identified metabolite, an initial conversion of HMDB (http://www.hmdb.ca/, Wishart et al. 2018) to KEGG (http://www.genome.jp/kegg/, Kanehisa et al. 2017) identifiers was performed using the "Linked entries option" option in the KEGG REST Service (http://rest. genome.jp/link/compound/hmdb). For metabolites putatively assigned as lipids, the ones with KEGG identifiers with LIPID MAPS (Lipidomics Gateway, http://www. lipidmaps.org/, Fahy et al. 2009) correspondence were also converted using the "Linked entries option" option (http:// rest.genome.jp/link/compound/lipidmaps) and all were classified using LIPID MAPS classification. The remaining compounds with KEGG identifiers were classified using KEGG database classification. To assess the presence of this compounds in the Plantae Kingdom, a final conversion of LIPID MAPS identifiers to KEGG was performed and all KEGG identifiers were searched in the KNApSAcK database (http://kanaya.naist.jp/KNApSAcK/, Nakamura et al. 2014). For compounds with multiple annotations a manual curation was performed.

\section{Results}

\section{Apoplastic fluid extraction}

The APF extraction protocol developed, based on the vacuum infiltration (VIC) method allows the 


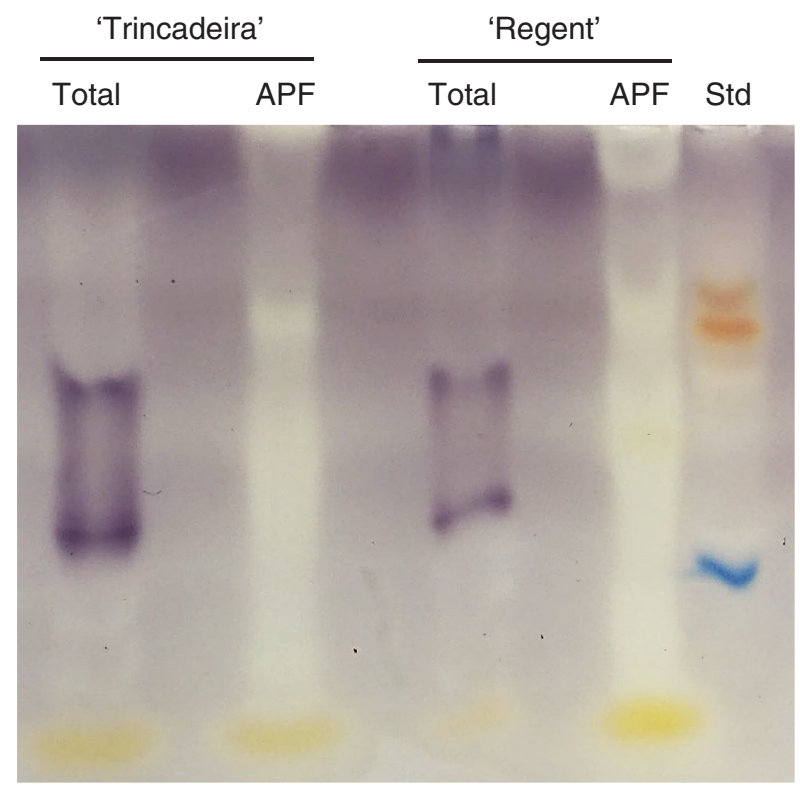

Fig 2. Malate dehydrogenase isoenzyme activity identification after isoelectric focusing (IEF) on polyacrylamide gels ( $\mathrm{pH} 3-10)$ stained with malate, NAD+ and nitroblue tetrazolium. MDH activity was evaluated on leaf extracts of total soluble proteins and APF proteins of Vitis vinifera cv. 'Trincadeira' (tri) and V. vinifera cv. 'Regent' (Reg). Fifteen micrograms of protein were loaded per lane; Std, IEF pre-color standard (BIO RAD 161-0310). The appearance of purple-blue bands indicates the presence of $\mathrm{MDH}$.

simultaneous extraction proteins and metabolites compatible with direct analysis by mass spectrometry. The infiltration buffer consisted of $0.1 \mathrm{M}$ Tris- $\mathrm{HCl}$ buffer $(\mathrm{pH}$ 8.0) solution containing $0.5 \mathrm{M} \mathrm{KCl}, 0.006 \mathrm{MCHAPS}$, and $2 \%(\mathrm{w} / \mathrm{v}) \mathrm{Na}_{2} \mathrm{SO}_{3}\left(\right.$ at $\left.4^{\circ} \mathrm{C}\right)$. The vacuum pressure used during leaf infiltration was of $25 \mathrm{kPa}$ and the total infiltration time to $3 \mathrm{~min}$ ( 6 periods of 30 seconds) to minimize cell integrity damage. By using reduced infiltration and centrifugation times, the overall duration of the extraction protocol was shortened, which is a highly critical issue in metabolomics to minimize the turnover and reactivity of cellular metabolites for the same grapevine starting material, 'Trincadeira' showed a slightly higher APF volume comparatively to 'Regent', 13 and $8 \mathrm{ml}$, respectively. Regarding protein yield, $1.7 \mathrm{mg}$ of 7 protein per gram of fresh weight $\left(\mathrm{mg} \mathrm{g}^{-1} \mathrm{FW}\right)$ was obtained for 'Trincadeira' and $1.2 \mathrm{mg} \mathrm{g}^{-1} \mathrm{FW}$ for 'Regent'.

\section{Purity assessment of apoplastic fluid}

The quality of the apoplastic fluid (absence of cytoplasmic content) was assessed by the malate dehydrogenase (MDH) enzymatic analysis by isoelectric focusing (IEF) gel electrophoresis. In addition, we have applied a fatty

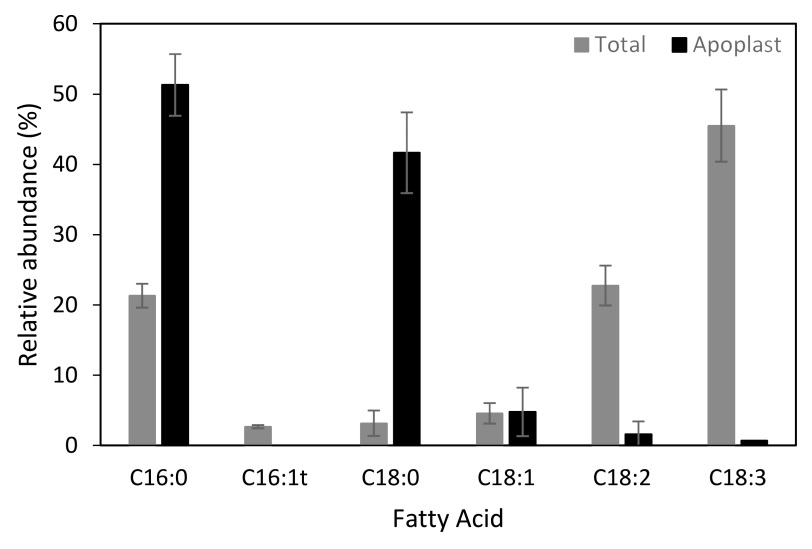

Fig 3. Percentage of the total fatty acids (FAs) identified in extracts of leaves and apoplastic fluids considering both grapevine genotypes. The values refer to the average of the FAs relative abundance in Vitis vinifera cvs 'Trincadeira' and 'Regent'. C16:0, Palmitic acid; C16:1t, trans-3-hexadecenoic acid; C18:0, Stearic acid; C18:1, Oleic acid; C18:2, linoleic acid; C18:3, $\alpha$-Linolenic acid.

acid (FA) analysis by gas chromatography (GC) to determine APF purity.

$\mathrm{MDH}$ activity was evaluated in the APF proteins and compared with total protein extracts. The appearance of purple-blue bands in total soluble protein extracts of both cultivars indicates the presence of $\mathrm{MDH}$, a cytoplasmic biomarker. No $\mathrm{MDH}$ was detected in the APF extracts (Fig. 2).

The abundance of trans-3-hexadecenoic acid (C16:1 $t$ ) was evaluated in total leaf extracts and APF extracts to assess the absence of cytosol contamination, since the C16:1-trans fatty acid containing phosphatidylglycerol (PG) molecular species is specific to chloroplast membranes (Eaton-Rye et al. 2011). FA composition of the APF extracts was assessed by GC (Fig. 3) and several FA were identified. C16:1 $t$ was detected in whole leaf extracts but not detected in the APF extracts.

\section{Proteomic analysis by nanoLC-MS/MS}

APF proteins were analyzed by nanoLC-MS/MS followed by homology search in NCBIprot Vitis vinifera database, allowing the identification of 721 proteins common to both cultivars (Supporting Information, Table S1). To further validate the extracellular nature of the identified proteins, several bioinformatic tools suitable for predicting protein secretion were used. Secretion of proteins can be predicted through the classical secretory pathways (SignalP 5.0, TargetP 1.1, ApoplastP, BUSCA, LocTree3 and Mercator) or through unconventional secretory pathways (SecretomeP; Table S2). Based on the obtained results, the 721 identified proteins were grouped in 4 different classes according to the following criteria: 
(1) proteins with a predicted signal peptide (SP) by SignalP (Class I, 44\%); (2) proteins predicted to be secreted through classical secretory pathways but, by other software than SignalP 5.0 (Class II, 36\%); (3) proteins predicted to be secreted by unconventional secretory pathways (USP) based on SecretomeP (Class III, 7\%), and proteins with no predicted secretion (Class IV, 13\%). The proteins from the Class IV could eventually be a result of symplastic co-extraction with APF (although no MDH was detected) or unknown leaderless secreted proteins that were not predicted by SecretomeP. The functional categorization of the 629 proteins belonging to Classes I, II and III, based on MapMan "Bin" and GO annotation, indicated that those proteins are mostly involved in: cell wall metabolism, protein metabolism and response to biotic and abiotic stress (Fig. 4).

\section{Metabolomic analysis by FT-ICR-MS}

After the ultrafiltration of the APF extracts on the Vivaspin ${ }^{\circledR}$ columns, the metabolites present in the APF lower fraction $(<10 \mathrm{kDa})$ were analyzed by Fourier-Transform lon-Cyclotron-Resonance Mass Spectrometry (FT-ICRMS) through an untargeted approach. To increase metabolome coverage, samples were analyzed in both positive $\left(\mathrm{ESI}^{+}\right)$and negative $\left(\mathrm{ESI}^{-}\right)$ionization modes (a representative spectrum of an $\mathrm{ESI}^{+}$analysis is shown in Fig. S1).

A total of 15096 and 15432 ion peaks were detected for 'Trincadeira' and 'Regent', respectively, in both ionization modes. The obtained mass lists were submitted to MassTRIX and the metabolite search for annotation was performed in the databases KEGG, HMDB and LipidMaps. A total of 1100 putative metabolites were annotated for 'Trincadeira' and 1657 for 'Regent' (Table 1). Of the putative annotated metabolites, 514 were common to both grapevine genotypes. The main metabolic classes represented were 'Lipids', followed by 'Phenolic compounds' and 'Carbohydrates' (Fig. 5, Table S3).

\section{Proteins and metabolites that participate in the same biochemical pathways}

Ten representative proteins and metabolites were selected based on their participation in the same biochemical pathways (substrates, reaction products or regulation of protein function). All of the selected proteins belong to classes I and II (proteins with a predicted SP and predicted to be secreted through classical secretory pathways), being involved in cell wall metabolism (beta-xylosidase/alpha-L-arabinofuranosidase,

heparanase-like protein 3, L-ascorbate oxidase-like, D-glucuronate, luteolin 7-o-glucoronide and L-ascorbate), protein metabolism and defense (cucumisin isoform X1,

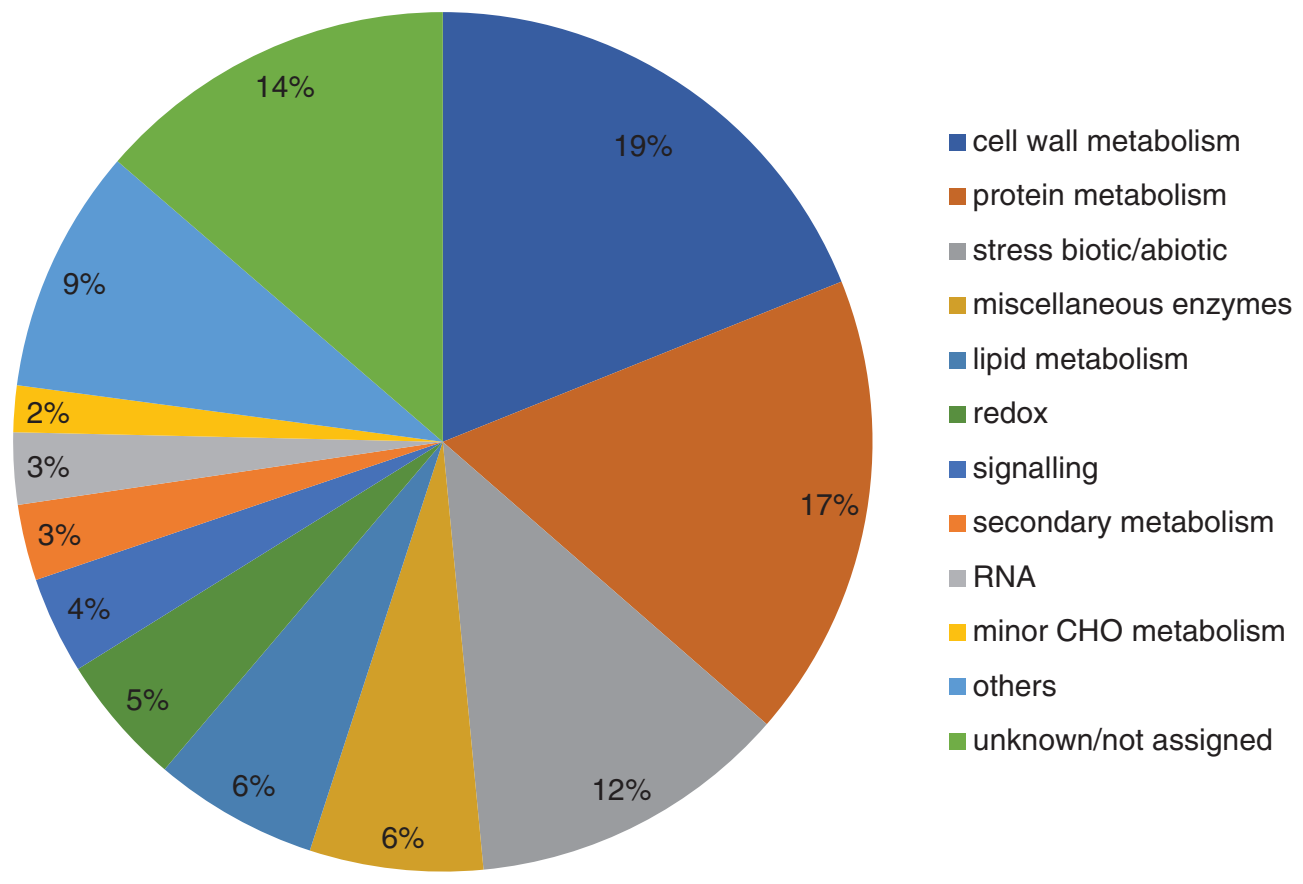

Fig 4. Biological process of the identified proteins commonly assigned in the APF of Vitis vinifera cvs 'Trincadeira' and 'Regent', based on Blast2GO and MapMan 'bin' annotation. 
Table 1. Number of obtained peaks after analysis of the Vitis vinifera cvs. 'Trincadeira' (Tri) and 'Regent' (Reg) APF samples by FT-ICR-MS and number of annotated masses in $\mathrm{ESI}^{+}$and $\mathrm{ESI}^{-}$ionization modes.

\begin{tabular}{llll}
\hline Ionization mode & Cultivar & Number of peaks $(\mathrm{m} / \mathrm{z})$ & Number of annotated masses \\
\hline $\mathrm{ESI}^{+}$ & Tri & 7071 & 846 \\
& Reg & 6309 & 1189 \\
$\mathrm{ESI}^{-}$ & Tri & 8025 & 254 \\
& Reg & 9123 & 468 \\
& Total & 30528 & 2757 \\
\hline
\end{tabular}

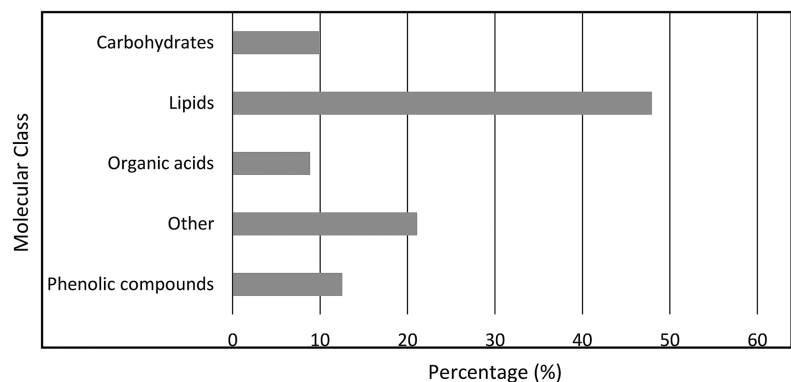

Fig 5. Major metabolic classes of the compounds commonly assigned in the APF of Vitis vinifera cvs 'Trincadeira' and 'Regent'.

chitotriosidase-1, acidic phosphatase 1, jasmonic acid, linoleic acid, N-acetyl-D-glucosamine, sinapyl-alcohol, riboflavin); lipid metabolism (non-specific lipidtransfer protein, hexadecanoic acid, octadecanoic acid, sn-glycero-3-phospho-1-inositol), polyamine metabolism (polyamine oxidase, spermidine) and carbohydrate metabolism (alpha-amylase, sucrose, gibberellin; Table 2).

\section{Discussion}

Understanding apoplast dynamics is essential to elucidate how plants respond to the surrounding environment, how these components interact between themselves, with the plasma membrane and the cell wall. These interactions are crucial for a comprehensive overview of cell communication, transport and how plant performance is affected. In grapevine, leaf ECS has been overlooked with only two studies published so far (Delaunois et al. 2013, Guillier et al. 2015). This study describes a VIC protocol for $V$. vinifera leaves for the simultaneous extraction of apoplastic proteins and metabolites from a single sample. The VIC protocol involves two critical steps. The first step is the vacuum pressure applied together with the composition of the infiltration solution, and the second step is the centrifugation force used (O'Leary et al. 2014). This protocol allowed us to use a small amount of grapevine leaves as well as a short extraction time, while maintaining cellular integrity and a good protein yield.
The reduction of the initial amount of grapevine leaves can be highly important for several experimental studies (e.g. biotic or abiotic stress imposition) where the available biological material can be a critical point. The infiltration solution, a Tris- $\mathrm{HCl}$ buffer containing $\mathrm{KCl}$, $\mathrm{Na}_{2} \mathrm{SO}_{3}$ and CHAPS, allowed the simultaneous extraction of proteins and metabolites, without sample oxidation. The presence of $\mathrm{KCl}$ in the APF infiltration buffer of different woody plant species has been extensively used (Pechanova et al. 2010, Guerra-Guimarães et al. 2014). The $\mathrm{KCl}$ led to the additional extraction of glycoproteins and guaranteed weakly bound cell wall proteins solubilization with low cytoplasm leaking (Regalado and Ricardo 1996). The sodium sulfite $\left(\mathrm{Na}_{2} \mathrm{SO}_{3}\right)$ minimizes the damage caused by oxidation (avoiding browning reactions; Schmid et al. 2017), being equally efficient as 2-mercaptoethanol or DTT but with less health and environmental hazards for a safer handling. On the other hand, CHAPS, a zwitterionic detergent, helps in protein and lipid solubilization (Hjelmeland 1980, Banerjee et al. 1990) while preserving the native functional state of the extracted proteins allowing to perform enzymatic assays in the APF extracts. A reduction in the overall duration of the extraction protocol was achieved, which is a very important parameter to mitigate the proteolytic activity and minimize the turnover and reactivity of cellular metabolites, fundamental for the success of proteomic and metabolomics analysis (Lu et al. 2017; Fig. 1A).

After APF extraction, the volume obtained for each genotype varied between 13 and $8 \mathrm{ml}$ for 'Trincadeira' and 'Regent', respectively. The contrasting mature leaves morphology of the two genotypes, reflecting variations in the histological structure, may influence the effectiveness of vacuum infiltration and APF extraction. According to the descriptors of the Vitis International Variety Catalog (Maul and Töpfer 2015), 'Trincadeira' presents a medium density of prostate hairs between the main veins on the lower side of the blade (OIV084) while 'Regent' presents a low density. The goffering of the blade is also contrasting with 'Trincadeira' presenting a very strong goffering and 'Regent' an absent or very weak (OIV072) (Fig. 6). Also, considering mesophyll organization and thickness, 'Trincadeira' presents a denser mesophyll than 'Regent'. 


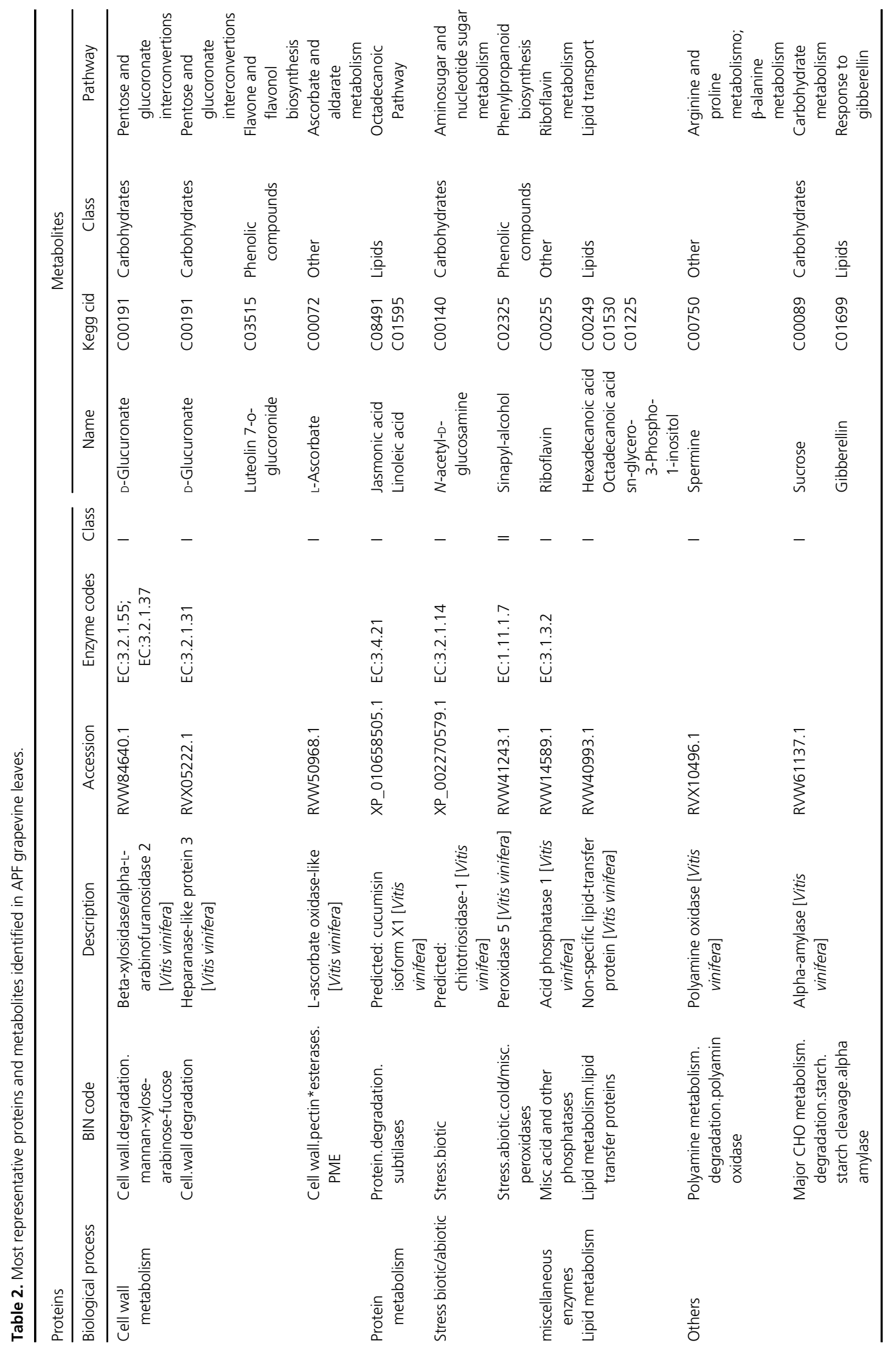



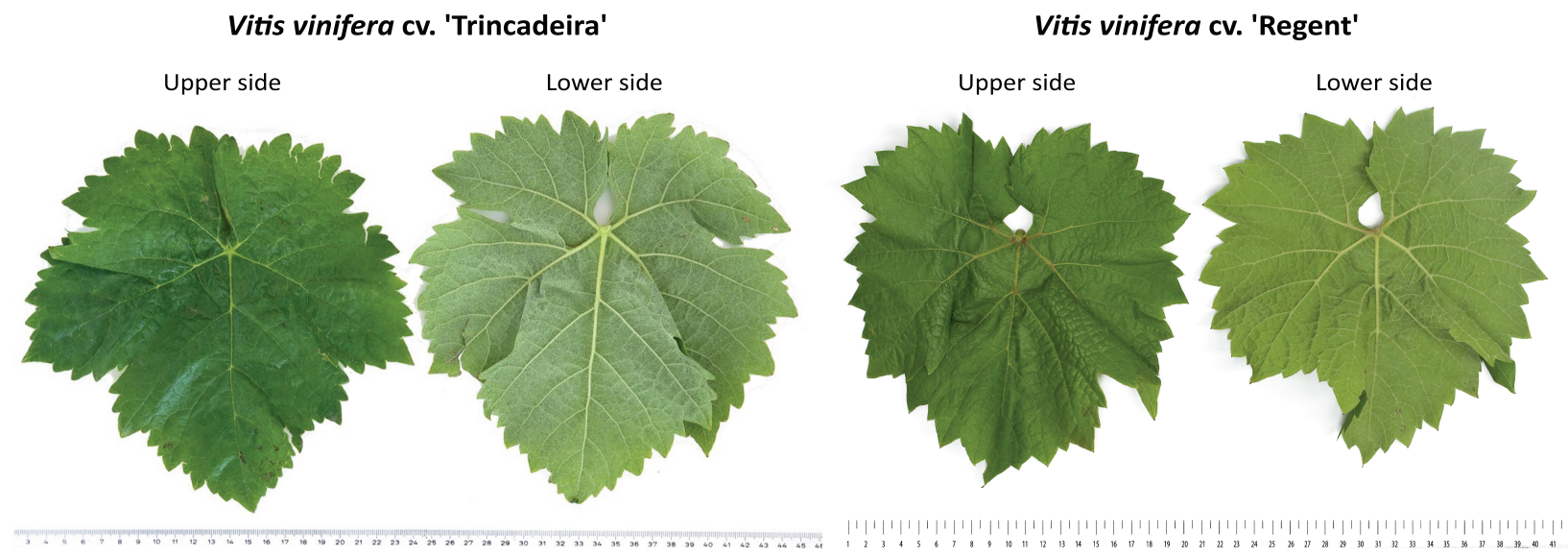

Fig 6. Differences between mature leaves: Upper side and lower side of blade from in Vitis vinifera cvs. 'Trincadeira' and 'Regent'. *Photo credit: Doris Schneider, Ursula Brühl, Julius Kühn-Institut (JKI), Federal Research Centre for cultivated plants, Institute for Grapevine Breeding Geilweilerhof, 76833 Siebeldingen, Germany.

Even though different volumes were obtained, in terms of protein yield, the values obtained were $1.7 \mathrm{mg} \mathrm{g}^{-1} \mathrm{FW}$ for 'Trincadeira' and $1.2 \mathrm{mg} \mathrm{g}^{-1} \mathrm{FW}$ for 'Regent', thus highlighting the robustness of this protocol.

The cytosolic biomarker malate dehydrogenase commonly used by several authors in different plant species (Fink et al. 1988, Pechanova et al. 2010, GuerraGuimarães et al. 2015) was applied for purity assessment of the extracted apoplastic fluid. Furthermore, we have also used C16:1t, a chloroplast membrane lipid FA (Eaton-Rye et al. 2011) as a new cytosolic marker to access apoplast integrity. Neither malate dehydrogenase activity nor the C16:1t were detected in the APF extracts confirming cell integrity maintenance in both grapevine varieties studied.

Regarding proteomic analysis and comparing the results obtained in this work with the previously reported by Delaunois et al. (2013) for grapevine leaf proteome, we were able to raise proteome coverage from 177 to 721 identified proteins. The functional annotation of the 721 identified proteins covered several biological processes as 'cell wall metabolism', 'protein metabolism' and 'response to stress'. These findings are in accordance with previous data obtained for leaf APF proteins not only in grapevine but also for other plants, despite the different analytical techniques used (Chivasa et al. 2005, Pechanova et al. 2010, Guerra-Guimarães et al. 2014, 2015, O'Leary et al. 2016).

Several bioinformatic tools were used to predict cellular localization of the identified proteins. Around $80 \%$ of the identified APF proteins carried an $\mathrm{N}$-terminal SP reaching their destination by the classical secretory pathway. Data from other research groups also indicated a high percentage of $\mathrm{N}$-terminal SP in APF proteins, e.g. $94 \%$ for Arabidopsis (Boudart et al. 2005), $90 \%$ for coffee (Guerra-Guimarães et al. 2014), 66\% for grapevine (Delaunois et al. 2013) and $65 \%$ for soybean (Subramanian et al. 2009). However, the presence of proteins lacking SP, leaderless secreted proteins (LSP) or non-classically secreted proteins (Agrawal et al. 2010) were about $7 \%$ of the identified proteins in this work. These LSPs have been also referred to in other APF studies (Ding et al. 2012, 2014, Guerra-Guimarães et al. 2014, O'Leary et al. 2016). According to Rabouille (2017), unconventional protein secretion is complex and comprises many issues such as proteins without a SP or a transmembrane domain that can translocate across the plasma membrane, and proteins that reach the plasma membrane by bypassing the Golgi despite entering the endoplasmic reticulum.

The untargeted metabolomics approach allowed the identification of 514 unique putative compounds and revealed that APF was enriched in lipids, carbohydrates and phenolic compounds. Moreover, while assessing APF purity through fatty acid profiling by GC, we were also able to identify saturated (C16:0 and C18:0) and unsaturated FAs oleic, linoleic and $\alpha$-linolenic acids (C18:1, C18:2 and C18:3). These FA were previously identified on grapevine leaves (Laureano et al. 2018, Cavaco et al. 2019). In French bean, both $\alpha$-linolenic and linoleic acids were detected in the APF (Bolwell et al. 2002). While in the APF the saturated FA was in higher abundance than unsaturated FA, in the total cell extract the opposite was observed (Fig. 3). This difference may be due to the fact that the total extract includes cell membranes, where the unsaturated FA are the major components of their lipids (Wewer et al. 2013, Kobayashi 2016). 
The few studies concerning APF metabolomics focus mainly on plant-pathogen interactions (Floerl et al. 2012, O'Leary et al. 2016, Green et al. 2020). GC-MS analysis of Phaseolus vulgaris APF after infection with the halo blight pathogen Pseudomonas syringae pv. phaseolicola revealed 60 compounds being the most abundant metabolites organic acids and carbohydrates (O'Leary et al. 2016). Floerl et al. (2012) also performed a metabolic fingerprinting by UPLC-MS of Arabidopsis thaliana APF after inoculation with Verticillium longisporum and identified 17 infection markers belonging to lipids, organic acids, bioactive fatty acids and phenolic compounds.

We have selected a set of 10 representative proteins and metabolites that might be interconnected in different biochemical pathways, like cell wall and protein metabolism (Table 2). In cell wall metabolism, beta-xylosidase/ alpha-L-arabinofuranosidase, previously identified in the APF of grapevine (Delaunois et al. 2013), coffee (Guerra-Guimarães et al. 2015), poplar (Pechanova et al. 2010) and tobacco (Dani et al. 2005), is an enzyme responsible for the hydrolysis of 1,4- $\beta$-D-xylan and arabinan in D-xyl and L-ara (Montes et al. 2008). D-xyl metabolite is the precursor of the pentose and glucuronate interconversions pathway. One of the metabolites involved in this pathway is D-glucuronate, which was found in the APF metabolome sequencing performed. Heparanase is a protein related to cell wall metabolism already described in both grapevine and poplar APFs (Pechanova et al. 2010, Delaunois et al. 2013). This enzyme catalyzes the conversion of luteolin 7 -O-[ $\beta$-D-glucuronosyl-( $\rightarrow 2$ )- $\beta$-D-glucuronide]$4^{\prime}$-O- $\beta$-D-glucuronide to luteolin 7-O-[ $\beta$-D-glucuronosyl$(1 \rightarrow 2$ )- $\beta$-D-glucuronide], releasing D-glucuronate from the reaction (Schulz and Weissenböck 1987). The luteolin-7-oglucoronide, found in the grapevine leaf APF, is a metabolite precursor of this reaction. L-ascorbate oxidase belongs to the ascorbate and aldarate metabolism pathway using Lascorbate as substrate (Pignocchi et al. 2003). Both enzyme and metabolite were identified in our grapevine APF. Having a role in protein and lipid metabolisms, cucumisin, a serine protease from the subtilase family, was identified. Serine proteases, previously identified in grapevine, coffee and poplar APFs (Pechanova et al. 2010, Delaunois et al. 2013, Guerra-Guimarães et al. 2015) were described to be involved in the octadecanoic pathway catalyzing the maturation of prosystemin into systemin (Bergey et al. 1996). Systemin activates a lipase in receptor cell membranes resulting in the release of $\alpha$-linolenic acid, the jasmonic acid precursor. Both $\alpha$-linolenic acid and jasmonic acid were found in APF metabolome. $\alpha$-Linolenic acid was already detected in French bean apoplast (Bolwell et al. 2002). In the biochemical pathways associated to plant defense to both biotic and abiotic stresses, we have identified a chitotriosidase, an enzyme that participates in the amino sugar and nucleotide sugar metabolism pathway through the hydrolysis of chitin in $\mathrm{N}$-acetyl-D-glucosamine (Dahiya et al. 2006). This last metabolite was also detected in the grapevine APF metabolome. Peroxidase 5, as well as sinapyl alcohol, was also identified in our analysis. This enzyme is involved in the phenylpropanoid biosynthesis pathway through the conversion of sinapyl into syringyl lignin (Sasaki et al. 2006, NovoUzal et al. 2014). Peroxidase was already detected in poplar and tobacco APFs (Dani et al. 2005, Pechanova et al. 2010). Acid phosphatase 1, previously reported in the apoplast of pea root nodules (Sujkowska et al. 2006), catalyzes reactions in the thiamine and riboflavin metabolism pathways (Yamato et al. 2000, Rapala-Kozik et al. 2008). Riboflavin, detected in the grapevine APF, is the reaction product of riboflavin-5-phosphate dephosphorylation, catalyzed by this enzyme (Yamato et al. 2000). Riboflavin was previously identified in Hyoscyamus albus APF (Higa et al. 2012).

Considering lipid metabolism, non-specific lipidtransfer proteins interact with several lipid molecules (Liu et al. 2015), namely hexadecanoic, octadecenoic acids and phospholipid sn-glycero-3-phospho-1-inositol, also found in our APF. In poplar apoplast, these non-specific lipid-transfer proteins have been already reported (Pechanova et al. 2010). Belonging to polyamine metabolism, we found polyamine oxidase, previously reported in APF of oat (Li and McClure 1989) and tobacco (Gémes et al. 2017). This enzyme participates in arginine and proline (Xiong et al. 2017) as well as $\beta$-alanine (Gurung et al. 2012) metabolic pathways. One of the reactions catalyzed by this enzyme is the conversion of spermine in spermidine (Gurung et al. 2012). Spermidine was found in our metabolome characterization. Alpha-amylase participates in carbohydrate metabolism (Damaris et al. 2019) and is responsive to gibberellin (Nanjo et al. 2004). Alpha-amylase, sucrose, sucrose derivatives and gibberellin were found in the grapevine APF.

In this work, we developed a method for the simultaneous extraction of proteins and metabolites from the same APF sample and improved the amenability for MS analysis and compatibility with several OMICs technologies. As a proof of concept, the methodology was tested in two different grapevine cultivars, with contrasting leaf morphology, and over 700 proteins and 500 metabolites were identified by MS, common to both grapevine cultivars. The major grapevine fatty acids were also analyzed by GC.

The proposed methodology opens new insights for global characterization of plant APF, searching compartment complexity and paving the way to uncover signaling networks and interactions within a systems biology approach. 


\section{Author contributions}

A.F. and L.G.G. conceived the study; J.E.D. and J.C. were responsible for the plant material; J.F., L.G.G. and A.R.C. optimized the APF extraction method; M.S.S., C.C., J.F. and A.R.C. performed the metabolome profiling by FT-ICR-MS; A.R.C. and A.R.M. performed the fatty acid profiling through GC; C.L. and J.R. performed the proteome profiling by nanoLC-MS/MS; J.F., A.R.C., A.F. and L.G.G. analyzed the data and wrote the manuscript. All of the authors have read and corrected the manuscript.

Acknowledgements - The present work was supported by: Portuguese Foundation for Science and Technology (FCT, Portugal) funded fellowships and contracts to AF, MSS, ARC and JF: IF/00819/2015, CEECIND/02246/2017, SFRH/ BD/131030/2017, SFRH/BD/137066/2018, respectively. FCT funded the Research Units and project: BiolSI (UIDB/04046/2020 and UIDP/04046/2020), and LEAF (UID/AGR/04129/2019), and the project PTDC/BIABQM/28539/2017. We also acknowledge the support from the Portuguese Mass Spectrometry Network (LISBOA01-0145-FEDER-022125) and the Project EU_FT-ICR_MS, funded by the Europe and Union"s Horizon 2020 research and innovation programme under grant agreement nr. 731077. We thank Dr. Rita B. Santos, Msc. Marisa Maia and Msc. Rui Nascimento for the critical review of the manuscript.

\section{Data availability statement}

The mass spectrometry proteomics data have been deposited to the ProteomeXchange Consortium via the PRIDE partner repository with the dataset identifier PXD015558 and 10.6019/PXD015558. The metabolomics data that support the findings of this study are available in figshare data repository through https://doi.org/ 10.6084/m9.figshare.12341216.v1

\section{References}

Agrawal GK, Jwa N-S, Lebrun M-H, Job D, Rakwal R (2010) Plant secretome: unlocking secrets of the secreted proteins. Proteomics 10: 799-827

Alexandersson E, Ashfaq A, Resjö S, Andreasson E (2013) Plant secretome proteomics. Front Plant Sci 4, 1-6

Almagro Armenteros JJ, Tsirigos KD, Sønderby CK, Petersen TN, Winther O, Brunak S, von Heijne G, Nielsen H (2019) SignalP 5.0 improves signal peptide predictions using deep neural networks. Nat Biotechnol 37: 420-423
Banerjee P, Buse JT, Dawson G (1990) Asymmetric extraction of membrane lipids by CHAPS. Biochim Biophys Acta 1044: 305-314

Bendtsen JD, Jensen LJ, Blom N, von Heijne G, Brunak S (2004) Feature-based prediction of non-classical and leaderless protein secretion. Protein Eng Des Sel 17: 349-356

Bergey DR, Howe GA, Ryan CA (1996) Polypeptide signaling for plant defensive genes exhibits analogies to defense signaling in animals. Proc Nat Acad Sci USA 93: 12053-12058

Blomster T, Salojärvi J, Sipari N, Brosché M, Ahlfors R, Keinänen M, Overmyer K, Kangasjärvi J (2011) Apoplastic reactive oxygen species transiently decrease auxin signaling and cause stress-induced morphogenic response in Arabidopsis. Plant Physiol 157: 1866-1883

Bolwell GP, Bindschedler LV, Blee KA, Butt VS, Davies DR, Gardner SL, Gerrish C, Minibayeva F (2002) The apoplastic oxidative burst in response to biotic stress in plants: a three-component system. J Exp Bot 53: 1367-1376

Boudart G, Jamet E, Rossignol M, Lafitte C, Borderies G, Jauneau A, Esquerré-Tugayé M-T, Pont-Lezica R (2005) Cell wall proteins in apoplastic fluids of Arabidopsis thaliana rosettes: identification by mass spectrometry and bioinformatics. Proteomics 5: 212-221

Cavaco AR, Figueiredo J, Laureano G, Sousa Silva M, Matos AR, Figueiredo A (2019) Subtilisin-like proteins and lipid signalling events: the missing links in grapevine resistance to Plasmopara viticola. Acta Hortic: 567-574

Chikov VI, Akhtyamova GA, Batasheva SN (2019) The role of extracellular space (apoplast) in the regulation of physiological processes in plants. WJASS 1:2-13

Chivasa S, Simon WJ, Yu X-L, Yalpani N, Slabas AR (2005) Pathogen elicitor-induced changes in the maize extracellular matrix proteome. Proteomics 5: 4894-4904

Conesa A, Götz S, García-Gómez JM, Terol J, Talón M, Robles M (2005) Blast2GO: a universal tool for annotation, visualization and analysis in functional genomics research. Bioinformatics 21: 3674-3676

Dahiya N, Tewari R, Hoondal GS (2006) Biotechnological aspects of chitinolytic enzymes: a review. Appl Microbiol Biotechnol 71: 773-778

Damaris RN, Lin Z, Yang P, He D (2019) The rice alphaamylase, conserved regulator of seed maturation and germination. Int J Mol Sci 20: 450

Dani V, Simon WJ, Duranti M, Croy RRD (2005) Changes in the tobacco leaf apoplast proteome in response to salt stress. Proteomics 5: 737-745

Delaunois B, Colby T, Belloy N, Conreux A, Harzen A, Baillieul F, Clément C, Schmidt J, Jeandet P, Cordelier $S$ (2013) Large-scale proteomic analysis of the grapevine leaf apoplastic fluid reveals mainly stress-related proteins and cell wall modifying enzymes. BMC Plant Biol 13: 24 
Delaunois B, Jeandet P, Clément C, Baillieul F, Dorey S, Cordelier S (2014) Uncovering plant-pathogen crosstalk through apoplastic proteomic studies. Front Plant Sci 5: 1-18

Deutsch EW, Csordas A, Sun Z, Jarnuczak A, PerezRiverol Y, Ternent T, Campbell DS, Bernal-Llinares M, Okuda S, Kawano S, Moritz RL, Carver JJ, Wang M, Ishihama Y, Bandeira N, Hermjakob H, Vizcaíno JA (2017) The ProteomeXchange consortium in 2017: supporting the cultural change in proteomics public data deposition. Nucleic Acids Res 45: D1100-D1106

Diaz-Vivancos P, Rubio M, Mesonero V, Periago PM, Ros Barceló A, Martínez-Gómez P, Hernández JA (2006) The apoplastic antioxidant system in Prunus: response to longterm plum pox virus infection. J Exp Bot 57: 3813-3824

Ding Y, Juan W, Junqi W, Stierhof Y-D, Robinson DG, Jiang L (2012) Unconventional protein secretion. Trends Plant Sc 17: 606-615

Ding Y, Robinson DG, Jiang L (2014) Unconventional protein secretion (UPS) pathways in plants. Current Opinion in Cell Biology, Cell organelles 29: 107-115

Diniz I, Azinheira H, Figueiredo A, Gichuru E, Oliveira H, Guerra-Guimarães L, Silva MC (2019) Fungal penetration associated with recognition, signaling and defencerelated genes and peroxidase activity during the resistance response of coffee to Colletotrichum kahawae. Physiol Mol Plant Pathol 105: 119-127

Dixon HH (1915) Transpiration and the ascent of sap in plants. Nature 94: 558-559

Eaton-Rye JJ, Tripathy BC, Sharkey TD (2011) Photosynthesis: Plastid Biology, Energy Conversion and Carbon Assimilation. Netherlands: Springer

Ellis JG, Dodds PN, Lawrence GJ (2007) The role of secreted proteins in diseases of plants caused by rust, powdery mildew and smut fungi. Curr Opin Microbiol 10: 326-331

Emanuelsson O, Brunak S, von Heijne G, Nielsen H (2007) Locating proteins in the cell using TargetP, SignalP and related tools. Nat Protoc 2: 953-971

Esquível MG, Matos AR, Marques Silva J (2017) Rubisco mutants of Chlamydomonas reinhardtii display divergent photosynthetic parameters and lipid allocation. Appl Microbiol Biotechnol 101: 5569-5580

Fahy E, Subramaniam S, Murphy RC, Nishijima M, Raetz CRH, Shimizu T, Spener F, van Meer G, Wakelam MJO, Dennis EA (2009) Update of the LIPID MAPS comprehensive classification system for lipids. J Lipid Res 50: S9-S14

Fink W, Liefland M, Mendgen K (1988) Chitinases and B1,3-glucanases in the apoplastic compartment of oat leaves (Avena sativa L.). Plant Physiol 88: 270-275

Floerl S, Majcherczyk A, Possienke M, Feussner K, Tappe H, Gatz C, Feussner I, Kües U, Polle A (2012) Verticillium longisporum infection affects the leaf apoplastic proteome, metabolome, and cell wall properties in Arabidopsis thaliana. PLoS One 7: e31435

Gémes K, Mellidou I, Karamanoli K, Beris D, Park KY, Matsi T, Haralampidis K, Constantinidou H-I, RoubelakisAngelakis KA (2017) Deregulation of apoplastic polyamine oxidase affects development and salt response of tobacco plants. J Plant Physiol 211: 1-12

Gentzel I, Giese L, Zhao W, Alonso AP, Mackey D (2019) A simple method for measuring apoplast hydration and collecting apoplast contents. Plant Physiol 179: 1265-1272

Goldberg T, Hecht M, Hamp T, Karl T, Yachdav G, Ahmed N, Altermann U, Angerer P, Ansorge S, Balasz K, Bernhofer M, Betz A, Cizmadija L, Do KT, Gerke J, Greil R, Joerdens V, Hastreiter M, Hembach K, Herzog M, Kalemanov M, Kluge M, Meier A, Nasir H, Neumaier U, Prade V, Reeb J, Sorokoumov A, Troshani I, Vorberg S, Waldraff S, Zierer J, Nielsen H, Rost B (2014) LocTree3 prediction of localization. Nucleic Acids Res 42: W350-W355

Granvogl B, Plöscher M, Eichacker LA (2007) Sample preparation by in-gel digestion for mass spectrometrybased proteomics. Anal Bioanal Chem 389: 991-1002

Green KA, Berry D, Feussner K, Eaton CJ, Ram A, Mesarich CH, Solomon P, Feussner I, Scott B (2020) Lolium perenne apoplast metabolomics for identification of novel metabolites produced by the symbiotic fungus Epichloë festucae. New Phytol 227: 559-571

Guerra-Guimarães L, Vieira A, Chaves I, Pinheiro C, Queiroz V, Renaut J, Ricardo CP (2014) Effect of greenhouse conditions on the leaf apoplastic proteome of Coffea arabica plants. J Proteomics 104: 128-139

Guerra-Guimarães LL, Tenente RER, Pinheiro CC, Chaves II, Silva MDCMLM, Cardoso FF, Planchon SS, De Barros DRD, Renaut JJ, Ricardo CPC (2015) Proteomic analysis of apoplastic fluid of Coffea arabica leaves highlights novel biomarkers for resistance against Hemileia vastatrix. Front Plant Sci 6: 478

Guerra-Guimarães L, Pinheiro C, Chaves I, Barros DR, Ricardo CP (2016) Protein dynamics in the plant extracellular space. Proteomes 4: 22

Guillier C, Gamm M, Lucchi G, Truntzer C, Pecqueur D, Ducoroy P, Adrian M, Héloir M-C (2015) Toward the identification of two glycoproteins involved in the stomatal deregulation of downy mildew-infected grapevine leaves. MPMI 28: 1227-1236

Gurung S, Cohen MF, Fukuto J, Yamasaki H (2012) Polyamine-induced rapid root abscission in Azolla pinnata. J Amino Acids, 2012: 1-9

Higa A, Khandakar J, Mori Y, Kitamura Y (2012) Increased de novo riboflavin synthesis and hydrolysis of FMN are involved in riboflavin secretion from Hyoscyamus albus hairy roots under iron deficiency. Plant Physiol Biochem 58: 166-173 
Hjelmeland LM (1980) A nondenaturing zwitterionic detergent for membrane biochemistry: design and synthesis. Proc Natl Acad Sci USA 77: 6368-6370

Kanehisa M, Furumichi M, Tanabe M, Sato Y, Morishima K (2017) KEGG: new perspectives on genomes, pathways, diseases and drugs. Nucleic Acids Res 45: D353-D361

Klement Z (1965) Method of obtaining fluid from the intercellular spaces of foliage and the fluid's merit as substrate for phytobacterial pathogens. Phytopathology 55: 1033-1034

Kobayashi K (2016) Role of membrane glycerolipids in photosynthesis, thylakoid biogenesis and chloroplast development. J Plant Res 129: 565-580

Krause C, Richter S, Knöll C, Jürgens G (2013) Plant secretome - from cellular process to biological activity. Biochim Biophys Acta Proteins Proteom 1834: 2429-2441

Laureano G, Figueiredo J, Cavaco AR, Duarte B, Caçador I, Malhó R, Sousa Silva M, Matos AR, Figueiredo A (2018) The interplay between membrane lipids and phospholipase A family members in grapevine resistance against Plasmopara viticola. Sci Rep 8: 1-15

Li Z, McClure JW (1989) Polyamine oxidase of primary leaves is apoplastic in oats but symplastic in barley. Phytochemistry 28: 2255-2259

Liu F, Zhang X, Lu C, Zeng X, Li Y, Fu D, Wu G (2015) Nonspecific lipid transfer proteins in plants: presenting new advances and an integrated functional analysis. J Exp Bot 66: 5663-5681

Lohaus G, Pennewiss K, Sattelmacher B, Hussmann M, Muehling KH (2001) Is the infiltration-centrifugation technique appropriate for the isolation of apoplastic fluid? A critical evaluation with different plant species. Physiol Plant 111: 457-465

Lohse M, Nagel A, Herter T, May P, Schroda M, Zrenner R, Tohge T, Fernie AR, Stitt M, Usadel B (2014) Mercator: a fast and simple web server for genome scale functional annotation of plant sequence data. Plant Cell Environ 37: 1250-1258

Loureiro A, Guerra-Guimarães L, Lidon FC, Bertrand B, Silva MC, Várzea V (2011) Isoenzymatic characterization of Colletotrichum kahawae isolates with different levels of aggressiveness. Trop Plant Pathol 36: 287-293

Lu W, Su X, Klein MS, Lewis IA, Fiehn O, Rabinowitz JD (2017) Metabolite measurement: pitfalls to avoid and practices to follow. Annu Rev Biochem 86: 277-304

Maia M, Monteiro F, Sebastiana M, Marques AP, Ferreira AEN, Freire AP, Cordeiro C, Figueiredo A, Sousa Silva M (2016) Metabolite extraction for high-throughput FTICR-MS-based metabolomics of grapevine leaves. EuPA Open Proteomics, 12: 4-9

MAMAOT (2012) Portaria $n^{\circ}$ 380/2012, de 22 de Novembro, do Ministério da Agricultura, do Mar, do Ambiente e do Ordenamento do Território (MAMAOT). Diário da República 1.a série-N. ${ }^{\circ} 226$, Lisbon
Maul E, Töpfer R (2015) Vitis international variety catalogue (VIVC): a cultivar database referenced by genetic profiles and morphology. BIO Web Conf 5: 01009

Misra BB (2016) The black-box of plant apoplast lipidomes. Front Plant Sci 7: 1-5

Montes RAC, Ranocha P, Martinez Y, Minic Z, Jouanin L, Marquis M, Saulnier L, Fulton LM, Cobbett CS, Bitton F, Renou J-P, Jauneau A, Goffner D (2008) Cell wall modifications in Arabidopsis plants with altered $\alpha-1-$ arabinofuranosidase activity. Plant Physiol 147: 63-77

Nakamura Y, Mochamad Afendi F, Kawsar Parvin A, Ono N, Tanaka K, Hirai Morita A, Sato T, Sugiura T, Altaf-UIAmin M, Kanaya S (2014) KNApSAcK metabolite activity database for retrieving the relationships between metabolites and biological activities. Plant Cell Physiol 55: e7

Nanjo Y, Asatsuma S, Itoh K, Hori H, Mitsui T, Fujisawa $\mathrm{Y}$ (2004) Posttranscriptional regulation of $\alpha$-amylase II-4 expression by gibberellin in germinating rice seeds. Plant Physiol Biochem 42: 477-484

Nascimento R, Maia M, Ferreira AEN, Silva AB, Freire AP, Cordeiro C, Silva MS, Figueiredo A (2019) Early stage metabolic events associated with the establishment of Vitis vinifera - plasmopara viticola compatible interaction. Plant Physiol Biochem 137: 1-13

Novo-Uzal E, Gutiérrez J, Martínez-Cortés T, Pomar F (2014) Molecular cloning of two novel peroxidases and their response to salt stress and salicylic acid in the living fossil Ginkgo biloba. Ann Bot 114: 923-936

O'Leary BM, Rico A, McCraw S, Fones HN, Preston GM (2014) The infiltration-centrifugation technique for extraction of apoplastic fluid from plant leaves using Phaseolus vulgaris as an example. J Vis Exp 94: e52113

O'Leary BM, Neale HC, Geilfus C-M, Jackson RW, Arnold DL, Preston GM (2016) Early changes in apoplast composition associated with defence and disease in interactions between Phaseolus vulgaris and the halo blight pathogen Pseudomonas syringae PV. phaseolicola. Plant Cell Environ 39: 2172-2184

Pechanova O, Hsu C-Y, Adams JP, Pechan T, Vandervelde L, Drnevich J, Jawdy S, Adeli A, Suttle JC, Lawrence AM, Tschaplinski TJ, Séguin A, Yuceer C (2010) Apoplast proteome reveals that extracellular matrix contributes to multistress response in poplar. BMC Genomics 11: 674

Pignocchi C, Fletcher JM, Wilkinson JE, Barnes JD, Foyer CH (2003) The function of ascorbate oxidase in tobacco. Plant Physiol 132: 1631-1641

Rabouille C (2017) Pathways of unconventional protein secretion. Trends Cell Biol 27: 230-240

Ramagli LS (1999) Quantifying protein in 2-D PAGE solubilization buffers. Proteom Anal Proto 2-D: 99-103

Rapala-Kozik M, Kowalska E, Ostrowska K (2008) Modulation of thiamine metabolism in Zea mays seedlings under conditions of abiotic stress. J Exp Bot 59: 4133-4143 
Regalado AP, Ricardo CP (1996) Study of the intercellular fluid of healthy Lupinus albus organs. Presence of a chitinase and a thaumatin-like protein. Plant Physiol 110: 227-232

Robertson EF, Dannelly HK, Malloy PJ, Reeves HC (1987) Rapid isoelectric focusing in a vertical polyacrylamide minigel system. Anal Biochem 167: 290-294

Ros-Barceló A, Gómez-Ros LV, Ferrer MA, Hernández JA (2006) The apoplastic antioxidant enzymatic system in the wood-forming tissues of trees. Trees 20: 145-156

Sasaki S, Baba K, Nishida T, Tsutsumi Y, Kondo R (2006) The cationic cell-wall-peroxidase having oxidation ability for polymeric substrate participates in the late stage of lignification of Populus alba L. Plant Mol Biol 62: 797-807

Sattelmacher B (2001) The apoplast and its significance for plant mineral nutrition. New Phytol 149: 167-192

Savojardo C, Martelli PL, Fariselli P, Profiti G, Casadio R (2018) BUSCA: an integrative web server to predict subcellular localization of proteins. Nucleic Acids Res 46: W459-W466

Schmid M, Prinz TK, Stäbler A, Sängerlaub S (2017) Effect of sodium sulfite, sodium dodecyl sulfate, and urea on the molecular interactions and properties of whey protein isolate-based films. Front Chem 4: 1-15

Schulz M, Weissenböck G (1987) Partial purification and characterization of a luteolin-triglucuronide-specific $\beta$-glucuronidase from rye primary leaves (Secale cereale). Phytochemistry 26: 933-937

Sebastiana M, Figueiredo A, Monteiro F, Martins J, Franco C, Coelho AV, Vaz F, Simões T, Penque D, Pais MS, Ferreira $S$ (2013) A possible approach for gel-based proteomic studies in recalcitrant woody plants. SpringerPlus 2: 210

Shaw CR, Prasad R (1970) Starch gel electrophoresis of enzymes - a compilation of recipes. Biochem Genet 4: 297-320

Sperschneider J, Dodds PN, Singh KB, Taylor JM (2018) ApoplastP: prediction of effectors and plant proteins in the apoplast using machine learning. New Phytol 217: 1764-1778

Subramanian S, Cho U-H, Keyes C, Yu O (2009) Distinct changes in soybean xylem sap proteome in response to pathogenic and symbiotic microbe interactions. BMC Plant Biol 9: 119

Suhre K, Schmitt-Kopplin P (2008) MassTRIX: mass translator into pathways. Nucleic Acids Res 36: W481-W484

Sujkowska M, Borucki W, Golinowski W (2006) Localization of acid phosphatase activity in the apoplast of pea (Pisum sativum L.) root nodules grown under phosphorus deficiency. Acta Physiol Plant 28: 263-271

Tseng T-T, Tyler BM, Setubal JC (2009) Protein secretion systems in bacterial-host associations, and their description in the gene ontology. BMC Microbiol 9: S2
Villiers F, Kwak JM (2013) Rapid apoplastic pH measurement in Arabidopsis leaves using a fluorescent dye. Plant Signal Behav 8: e22587

Vizcaíno JA, Csordas A, del-Toro N, Dianes JA, Griss J, Lavidas I, Mayer G, Perez-Riverol Y, Reisinger F, Ternent T, Xu Q-W, Wang R, Hermjakob H (2016) 2016 update of the PRIDE database and its related tools. Nucleic Acids Res 44: D447-D456

Wewer V, Dörmann P, Hölzl G (2013) Analysis and quantification of plant membrane lipids by thin-layer chromatography and gas chromatography. Plant Lipid Signal Proto, 1009: 69-78

Wishart DS, Feunang YD, Marcu A, Guo AC, Liang K, Vázquez-Fresno R, Sajed T, Johnson D, Li C, Karu N, Sayeeda Z, Lo E, Assempour N, Berjanskii M, Singhal S, Arndt D, Liang Y, Badran H, Grant J, Serra-Cayuela A, Liu Y, Mandal R, Neveu V, Pon A, Knox C, Wilson M, Manach C, Scalbert A (2018) HMDB 4.0: the human metabolome database for 2018. Nucleic Acids Res 46: D608-D617

Xiong H, Guo H, Xie Y, Zhao L, Gu J, Zhao S, Li J, Liu L (2017) RNAseq analysis reveals pathways and candidate genes associated with salinity tolerance in a spaceflightinduced wheat mutant. Sci Rep 7: 2731

Yamato S, Kawakami N, Shimada K, Ono M, Idei N, Itoh Y (2000) Preparation and characterization of immobilized acid phosphatase used for an enzyme reactor: evaluation in flow-injection analysis and pre-column liquid chromatography. Anal Chim Acta 406: 191-199

\section{Supporting information}

Additional supporting information may be found online in the Supporting Information section at the end of the article.

Table S1. nanoLC-MS/MS data obtained for the grapevine leaf apoplastic proteins identified using NCBI grapevine database.

Table S2. Annotation of the grapevine leaf apoplastic proteins based on MapMan 'BIN' categories and Blast2GO, and subcellular localization prediction using SignalP 5.0, TargetP 1.1, ApoplastP, BUSCA, LocTree3, Mercator and SecretomeP.

Table S3. Putative identification and classification of the detected metabolites in the APF of Vitis vinifera cvs 'Regent' and 'Trincadeira'.

Fig. S1. Representative mass spectra of Vitis vinifera low molecular mass APF. 